\title{
Correction to: Trend of Changes in Serum Albumin and Its Relation with Sex, Age, and BMI Following Laparoscopic Mini-gastric Bypass Surgery in Morbid Obese Cases
}

\author{
Mehrdad Karimi $^{1,2} \cdot$ Ali Kabir ${ }^{2} \cdot$ Masoumeh Nejatifar $^{3} \cdot$ Abdolreza Pazouki $^{2,4,5}$
}

Published online: 13 November 2017

(C) Springer Science+Business Media, LLC, part of Springer Nature 2017

\section{Correction to: OBES SURG}

https://doi.org/10.1007/s11695-017-2912-2

Due to a production error the bottom portion of Fig. 3 was missing in the version of this article originally published online. The corrected version of the article has now been published. The corrected version of the figure follows:

The online version of the original article can be found at https://oi.org/ 10.1007/s11695-017-2912-2

\section{Ali Kabir}

aikabir@yahoo.com

Mehrdad Karimi

karimi.mehrdad89@yahoo.com

Masoumeh Nejatifar

rnejatifar@gmail.com

Abdolreza Pazouki

apazouki@yahoo.com
Department of Surgery, Shahrekord University of Medical Sciences, Sharekord, Iran

2 Minimally Invasive Surgery Research Center, Iran University of Medical Sciences, Room 255, Central Building, Hemmat Expway, Tehran, Iran

3 Faculty of Health, ShahidBeheshti University of Medical Sciences, Tehran, Iran

4 Center of Excellence for Minimally Invasive Surgery Training, Iran University of Medical Sciences, Tehran, Iran

5 Center of Excellence of European Branch of International Federation for Surgery of Obesity, Tehran, Iran 


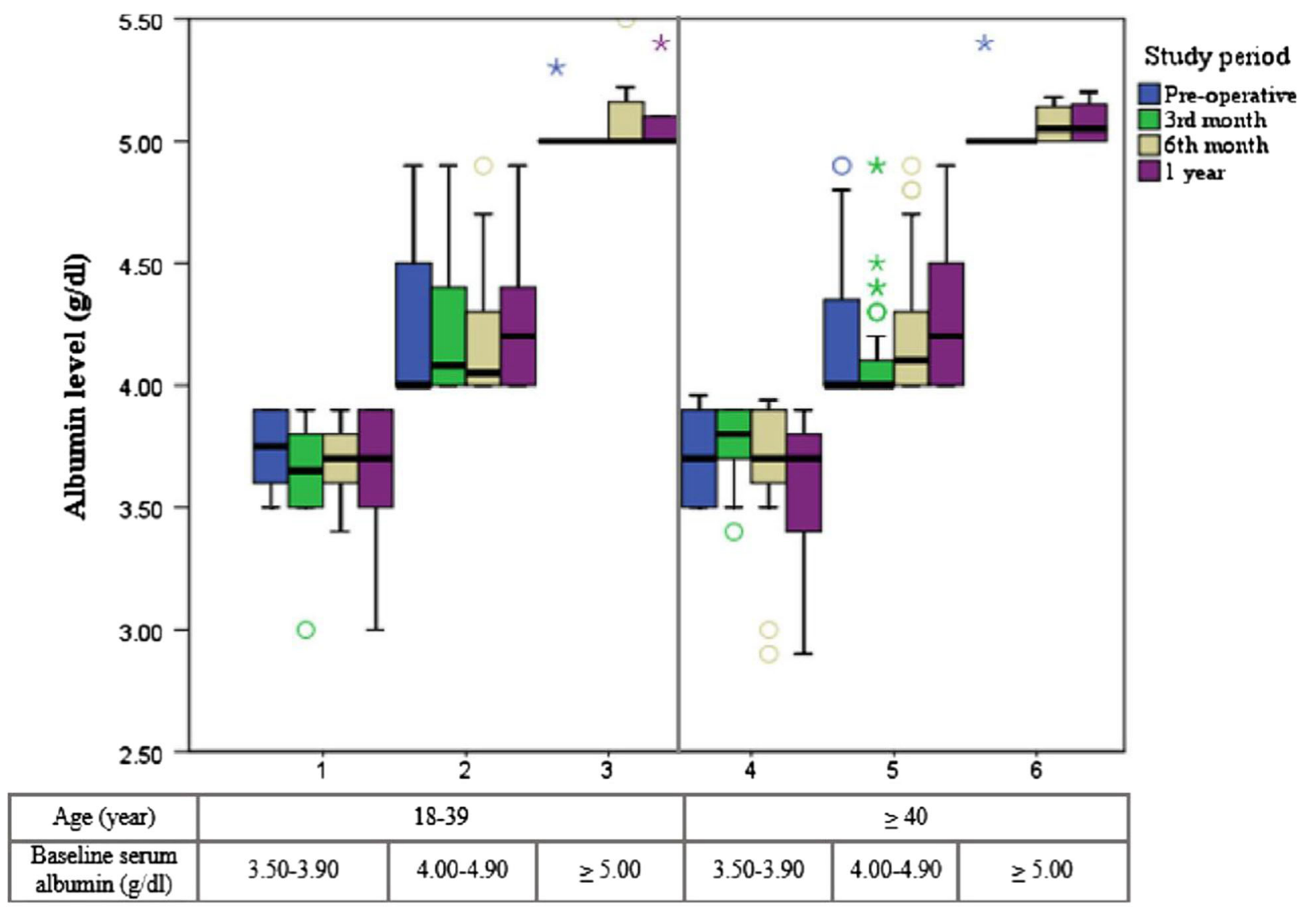

Groups of Age-Baseline serum albumin level 